\title{
Analysing Energy and Material Saving Technologies' Adoption and Adopters
}

\author{
Iztok Palčič ${ }^{1, *}$ - Marc Pons² - Andrea Bikfalvi² - Josep Llach² - Borut Buchmeister ${ }^{1}$ \\ 1 University of Maribor, Faculty of Mechanical Engineering, Slovenia \\ 2 Universitat de Girona, Spain
}

\begin{abstract}
The main objective of this paper is to map the adoption of technologies for energy reduction and resources consumption in production. The aim is also to contribute to the identification and understanding of the characteristics of the manufacturing firms that use these kinds of energy and material saving technologies. Our research is based on data from the largest European manufacturing survey to date and it includes data from Spain and Slovenia. The results show that the use of specific energy saving technologies and material saving technologies in manufacturing firms is still modest. Dividing manufacturing firms based on technology intensity sectors and based on their relative energy efficiency we have concluded that firms in high technology industries focus less on energy efficiency than low technology firms. Some other specific relationships between the use of energy efficient technologies and adopters' characteristics (e. g. use of environmental management systems) are presented in this paper.
\end{abstract}

Keywords: energy efficiency, manufacturing firm, energy saving technology, material saving technology, European manufacturing survey

\section{O INTRODUCTION}

Manufacturing is defined as the transformation of materials and information into goods for the satisfaction of human needs. Turning raw materials into consumer products is also a major source of environmental pollution. Waste coming from manufacturing activities is an environmental threat originating in several regions around the world [1]. Therefore, in recent years, mostly in response to increasing pressure from environmental regulations, many manufacturing firms have made significant efforts to use cleaner production methods [2] to [4].

Industrial energy efficiency plays a central role as the manufacturing industry accounts for about $75 \%$ of the world's yearly coal consumption, $44 \%$ of the world's natural gas consumption, and $20 \%$ of global oil consumption. In addition, these manufacturing firms also use $42 \%$ of all the electricity generated [5]. Although renewable energy technologies, such as photovoltaic technology, might be a long-term solution, more efficient energy use can make the greatest and most economic contribution towards solving these problems in the short run. Using the available energy more efficiently is an effective countermeasure to rising energy needs and insecure energy supplies [6] and[7]. Bunse et al. [8] argue that examples in the literature and in real world practice show that although the manufacturing sector has made continuous improvements in energy efficiency, the economically beneficial energy efficiency potential has not yet been fully exploited [8] to [10].

This paper is based on an empirical study in the field of energy and material efficiency technologies.
The objective of this paper is firstly to map the adoption of technologies for the reduction of energy and resource consumption in production and, second, to contribute to the identification and understanding of the characteristics of the manufacturing firms that use these kinds of innovative technologies.

The paper is organized as follows. The introduction comprises a background and literature review of energy efficiency in production. Next, the research methodology and methods used to analyse the characteristics of energy and material saving technologies' adoption and their adopters are presented. The results and findings are presented for the manufacturing firms with the use of descriptive statistics and simple correlation tests. Finally, we discuss our results and present some implications.

\section{LITERATURE REVIEW}

The energy efficiency of manufacturing processes is becoming increasingly important due to rising energy costs and climate altering greenhouse gas emissions [11]. Improving energy efficiency is regarded as one of the most important options for reducing greenhouse gas emissions and for reducing the dependency of countries on energy imports [12]. Measuring energy efficiency is the basis for controlling energy consumption in the production processes and for deciding on improvement measures, as well as for tracking changes and improvements in energy efficiency [8]. Studies on the energy consumption of manufacturing processes have provided fundamental information for improving energy efficiency and building a comprehensive foundation aimed at 
reducing the energy consumption of manufacturing processes [11]. There is also an on-going debate regarding the reasons why profitable investments to reduce energy consumption have not been carried out in companies [13] and [14]. There are several barriers to implementing energy efficiency improvement measures in firms, e. g. payback periods, limited capital, a low priority given to energy efficiency by the management, lack of information, or "difficult-tomeasure components" of energy investments [8] and [15] to [17].

Bunse et al. [8] argue that many industrial firms still lack appropriate methods to effectively address energy efficiency in production management. Current approaches to integrating energy efficiency performance as a relevant criterion in production management seem to have shortcomings in their comprehensiveness and practicality. The authors of this paper argue that there are two reasons for this: the first is that there is no consensus on the definition of energy efficiency. The second reason is the variety of ways of measuring and monitoring energy efficiency.

When discussing energy efficiency in the industrial sector, different definitions are used [8] and [18] to [21]. Bunse et al. [8] define energy efficiency as "the ratio of energy services out to energy input (meaning) getting the most out of every energy unit you buy". Increased energy efficiency may be accomplished by more efficient technology, energy recovery in the same process or further use of energy waste in different processes, increased energy conversion efficiency or optimized operational practices.

Energy efficiency developments can be monitored by quantifying the ratio of energy input and the useful output of a certain activity over time. The useful output of an activity can be defined in either physical (e.g. litres of beer produced or person kilometres driven) or monetary units (e.g. GDP of a country or value added of a sector) [12].

Energy efficiency indicators are usually ratios describing the relationship between an activity and the required energy. In the industrial sector, activities such as the production process of a product can be described in either economic or physical terms resulting in either economic or physical indicators. Economic indicators are useful at an aggregated level, such as for comparing different sectors; however, to gain insight into particular manufacturing processes, physical indicators are more suitable [22]. Examples of physical indicators are specific energy consumption [22] to [25], final energy efficiency improvement [26], thermodynamic energy efficiency [19], etc. There is no single energy efficiency indicator that can be applied in every situation, but the appropriate indicators have to be defined depending on the decision to be made or the decision tool to be applied [25].

Only several studies used for environmental variables the use of production activities or energy efficient technologies. One of the most recent is from Zeng et al. [27] who found an overall positive impact of cleaner production on firms' business performance, but not under all circumstances. They argue that the cleaner production activities from low-cost schemes (e. g. improve employee environmental consciousness through training, improve working conditions to reduce waste, strictly enforce rules on cleaner production, increase the recyclability of the products and components) make a bigger contribution to financial performance than high-cost scheme activities (e. g. using energy efficient and clean technologies or using renewable resources as raw materials), which require significant financial investment but may not result in immediate economic benefit. Thus, lowcost schemes for cleaner production activities do not require significant financial input but may bring immediate financial benefits.

\section{METHODOLOGY}

We used data from the European Manufacturing Survey (EMS) for our research. The EMS is the largest European survey on manufacturing activities and is coordinated by the Fraunhofer Institute for Systems and Innovation Research (ISI), Germany. The survey collects data on manufacturing strategies, the application of innovative organisational and technological concepts in production, personnel deployment and qualification, the production offshoring and back-sourcing activities, cooperation patterns, etc. Data on firm characteristics and performance indicators (R\&D expenses, productivity, returns on sales,) is also collected.

The 2009 EMS edition was carried out in 12 countries. This paper uses data from the Spanish and Slovenian sub-samples. The Spanish sub-sample had 116 responses and the Slovenian accounted for 64, altogether 180 responses. The survey was performed in manufacturing firms (NACE codes from 15 to 37) with at least 20 employees.

In recent years, only a few surveys in the world have been launched that analyse energy efficiency in manufacturing firms and their energy saving technologies (EST) and material saving technologies (MST) use. These existing surveys cover only some industrial sectors - monitoring very specific 
technologies or cover only American and Asian countries. None of them include the European countries covered by EMS, which also encompasses all manufacturing industries. The latest survey added several questions related to environmental and energy issues; the EMS defines 10 general groups of technologies: 8 for energy efficiency and 2 for material consumption saving. Any specific technology can be classified into one of these broad groups, thereby creating a global map of their use and level of implementation.

The EST included were:

T1. control system for shut down of machines in offpeak periods,

T2. electric motors with rotation speed regulation,

T3. compressed air contracting,

T4. highly efficient pumps,

T5. low-temperature joining processes,

T6. retrieval of kinetic and process energy,

T7. combined cold, heat and power - Bi-/Trigeneration and

T8. waste material for in-house energy generation. We included two MST:

T9. utilisation of recycled material in product manufacturing and

T10. product recovery after product life cycle.

EST and MST are characterized in terms of use and also in terms of usage levels (extent of use) through a descriptive and a frequency analysis. The extent of actual use is referred to by comparing the actual use of the technology in the firm to the most reasonable potential use. There are three levels: the extent of utilised potential is "low" for an initial attempt to utilise, "medium" for partly utilized, and "high" for extensive use.

We have analysed the characteristics of EST and MST adopters according to the OECD's taxonomy of manufacturing industries classified by their technological intensity [28]. We have formed three groups: "Low technology" with firms from NACE 1516, 17-19, 20-22, 36-37; "Medium-Low technology" with firms from NACE 23, 25, 26, 351, 27, 28; and "Medium-High and High technology" with firms from NACE 24, 31, 34 excl. 2423, 352+359, 29 and 353, $2423,30,32,33$. As shown in Table 1, the majority of firms fall within the Medium-Low technology group. If we join Medium-Low technology and MediumHigh technology, this group consists of 131 firms, thus making Medium technology industry the largest group. Since our High technology industry group (NACE 353, 2423, 30, 32 and 33) involves only 13 firms, this group was merged with the Medium-High technology industry group in order to reduce the number of groups. We created a discrete variable to group this classification into three categories: "Low technology" - value 1, "Medium-Low technology" - value 2, and "Medium-High and High technology" - value 3. "Medium-Low technology" was taken as a reference variable.

Next, we classified technology adopters into three groups that represent the relative energy and materials consumption efficiency in production. These groups were created from the responses to the question regarding the perception of their production efficiency in terms of actual material and energy consumption in comparison with other factories in their industry. Energy efficiency is therefore measured on a relative scale with values from 1 to 5 . The scale ranges from 1 meaning much less efficient $(0.5 \%)$ to a value of 5 meaning much more efficient $(2.2 \%)$. The value 2 indicates somewhat less efficient $(6.1 \%), 3$ indicates equally efficient $(62.6 \%)$, and 4 indicates somewhat more efficient $(28.5 \%)$. In the analyses, three groups have been created from this variable: "Less efficient" (firms rated with values 1 or 2), "Equally efficient" (firms rated with a value of 3) and "More efficient" (firms rated with values 4 or 5).

\section{RESULTS AND FINDINGS}

Table 1 presents the results according to the OECD's taxonomy of manufacturing industries classified by their technological intensity. The results show that adopters in higher technologically intensive industries have, on average, a higher number of employees, higher percentage of firms with R\&D expenditure, superior exportation intensity (more than $50 \%$ of sales abroad), and a strong use of environmental management systems, such as ISO 14000 [29]. Firms in Medium-high and High Technology industrial sectors also had an average turnover in 2008 of more than the double of each one of the other two technological groups (62 vs. 22 and $30 \mathrm{M€}$ ). From the average estimation of material and energy efficiency in production ( $\max$. range $=5$, min. range $=1$ ), there is hardly any difference between these groups of technological sectors relative to the average of material and energy efficiency in production.

Table 2 presents the results according to three groups representing the relative energy and materials consumption efficiency in production. There are only 12 firms in the "Less efficient" group. The majority of firms are in the "Equally efficient" group. There were only 4 firms that claimed that they were considerably more efficient than other firms in their industry. The "More efficient" group had altogether 55 firms. 
Table 1. Summary of descriptive features of the sample by technological intensity

\begin{tabular}{|c|c|c|c|c|}
\hline & Low technology & $\begin{array}{c}\text { Medium-Low } \\
\text { technology }\end{array}$ & $\begin{array}{l}\text { Medium-High and } \\
\text { High technology }\end{array}$ & Total \\
\hline $\mathrm{N}$ & $43(23 \%)$ & $82(44 \%)$ & $62(49+13)(33 \%)$ & 187 \\
\hline Number of employees 2008. $\mathrm{N}=187$ & 76 & 137 & 402 & 211 \\
\hline Turnover 2008. $\mathrm{N}=169$ & $30 \mathrm{M€}$ & $22 \mathrm{M€}$ & $62 \mathrm{M€}$ & $37 \mathrm{M€}$ \\
\hline Firms with $R \& D$ expenditures. $N=183$ & $50 \%$ & $53 \%$ & $75 \%$ & $60 \%$ \\
\hline High exportation intensity firms. $\mathrm{N}=172$ & $24 \%$ & $39 \%$ & $53 \%$ & $41 \%$ \\
\hline Firms with IS0 14000 implemented. $\mathrm{N}=187$ & $14 \%$ & $30 \%$ & $34 \%$ & $28 \%$ \\
\hline Average energy efficiency in production. $\mathrm{N}=179$ & 3.25 & 3.32 & 3.18 & 3.26 \\
\hline T1: Control system for machine shut down. $\mathrm{N}=179$ & $29 \%$ & $24 \%$ & $30 \%$ & $27 \%$ \\
\hline T2: Speed regulation. $\mathrm{N}=184$ & $57 \%$ & $51 \%$ & $62 \%$ & $56 \%$ \\
\hline T3: Compressed air contracting. $\mathrm{N}=182$ & $26 \%$ & $16 \%$ & $31 \%$ & $24 \%$ \\
\hline T4: Highly efficient pumps. $\mathrm{N}=181$ & $26 \%$ & $16 \%$ & $24 \%$ & $21 \%$ \\
\hline T5: Low-temperature joining processes. $\mathrm{N}=182$ & $0 \%$ & $9 \%$ & $15 \%$ & $9 \%$ \\
\hline T6: Energy retrieval. $\mathrm{N}=178$ & $10 \%$ & $7 \%$ & $9 \%$ & $8 \%$ \\
\hline T7: Bi-/Tri-generation. $\mathrm{N}=178$ & $5 \%$ & $6 \%$ & $12 \%$ & $8 \%$ \\
\hline T8: Waste material for energy. $\mathrm{N}=178$ & $10 \%$ & $9 \%$ & $10 \%$ & $10 \%$ \\
\hline T9: Recycled material in production. $\mathrm{N}=178$ & $45 \%$ & $30 \%$ & $34 \%$ & $35 \%$ \\
\hline T10: Product recovery. $\mathrm{N}=178$ & $35 \%$ & $26 \%$ & $28 \%$ & $29 \%$ \\
\hline
\end{tabular}

Table 2. Summary of descriptive features of the sample by relative efficiency in production

\begin{tabular}{|c|c|c|c|c|}
\hline & Less efficient & Equally efficient & More efficient & Total \\
\hline $\mathrm{N}$ & $12(1+11)(7 \%)$ & $112(63 \%)$ & $55(51+4)(30 \%)$ & 179 \\
\hline Number of employees 2008. $\mathrm{N}=179$ & 140 & 146 & 377 & 216 \\
\hline Turnover 2008. $\mathrm{N}=164$ & $13 \mathrm{M€}$ & $23 \mathrm{M} €$ & $64 \mathrm{M€}$ & $38 \mathrm{M€}$ \\
\hline Firms with $\mathrm{R} \& D$ expenditures. $\mathrm{N}=176$ & $58 \%$ & $61 \%$ & $60 \%$ & $61 \%$ \\
\hline High exportation intensity firms. $\mathrm{N}=165$ & $64 \%$ & $42 \%$ & $37 \%$ & $42 \%$ \\
\hline Firms with IS0 14000 implemented. $\mathrm{N}=179$ & $33 \%$ & $17 \%$ & $45 \%$ & $28 \%$ \\
\hline Average of Technological intensity. $\mathrm{N}=179$ & 2.23 & 2.13 & 2.07 & 2.12 \\
\hline T1: Control system for machine shut down. $\mathrm{N}=171$ & $33 \%$ & $21 \%$ & $42 \%$ & $28 \%$ \\
\hline T2: Speed regulation. $\mathrm{N}=176$ & $42 \%$ & $50 \%$ & $75 \%$ & $57 \%$ \\
\hline T3: Compressed air contracting. $\mathrm{N}=174$ & $17 \%$ & $25 \%$ & $25 \%$ & $24 \%$ \\
\hline T4: Highly efficient pumps. $\mathrm{N}=173$ & $8 \%$ & $20 \%$ & $28 \%$ & $22 \%$ \\
\hline T5: Low-temperature joining processes. $\mathrm{N}=174$ & $8 \%$ & $8 \%$ & $11 \%$ & $9 \%$ \\
\hline T6: Energy retrieval. $\mathrm{N}=170$ & $0 \%$ & $7 \%$ & $15 \%$ & $9 \%$ \\
\hline T7: Bi-/Tri-generation. $\mathrm{N}=170$ & $8 \%$ & $7 \%$ & $9 \%$ & $8 \%$ \\
\hline T8: Waste material for energy. $\mathrm{N}=170$ & $0 \%$ & $9 \%$ & $15 \%$ & $10 \%$ \\
\hline T9: Recycled material in production. $\mathrm{N}=170$ & $42 \%$ & $32 \%$ & $39 \%$ & $35 \%$ \\
\hline T10: Product recovery. $\mathrm{N}=170$ & $0 \%$ & $29 \%$ & $37 \%$ & $30 \%$ \\
\hline
\end{tabular}

Regarding energy and materials efficiency, descriptive analysis shows that firms belonging to the more relatively efficient groups have, on average, higher numbers of employees (much more than equally or less efficient firms: 377 vs. 146 and 140). Average firm turnover also increases as the relative efficiency of these firms increases (the "More efficient" group has an average turnover of 64 vs. 23 and $13 \mathrm{M} €$ ). However, high exportation intensity (more than $50 \%$ of sales abroad) is reduced on average as the studied groups gain relative efficiency. Looking at the technological intensity of the firms we can see a slight decrease in the technological intensity values from the "Less efficient" group to the "More efficient" group. And finally, looking at R\&D expenditure and the use of environmental management systems, such as ISO 14000, hardly any trend is visible. Interestingly, the average use of environmental management systems in the "Equally efficient" group is much smaller than in the "Less efficient" group.

Fig. 1 depicts the use of EST and MST for all manufacturing sectors presented. Here we see that 
"Speed control" is the most highly used technology with $56 \%$ of affirmative responses. The second and third place technologies in the use ranking MST were "Recycled material in production" with a $35 \%$ and "Product recovery" with a 29\%. The second EST "Control system for shut down of machines in off-peak periods" (27\%) is in the fourth position and has much lower use than the top ranking "speed control." However, the highest ranking "Speed control" technology and its large lead over the other technologies could be misleading since this technology may be misunderstood or very broadly interpreted. The term "Electric motors with rotation speed regulation" can be understood to mean that almost any machine that produces any kind of motion or rotation with a common speed regulation system over the engine has implemented this technology. For most machines, however, this is not an option, but rather an intrinsic characteristic. Therefore, it is questionable whether "Speed control" should be considered an EST.

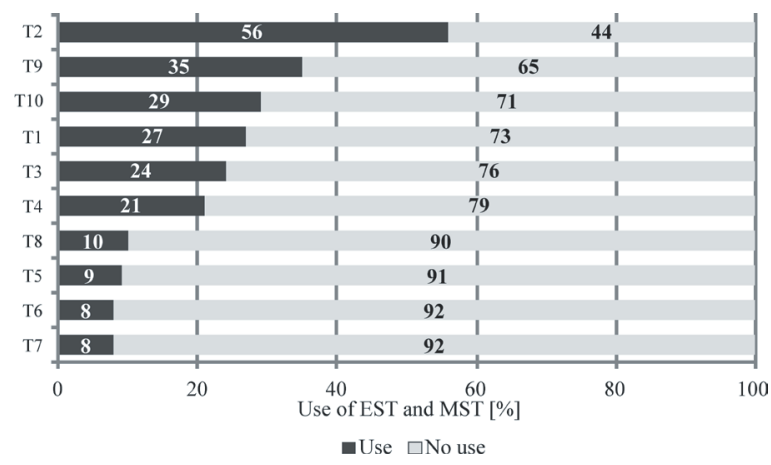

Fig. 1. Use of EST and MST for all manufacturing sectors

The graph in Fig. 2 shows a distribution of technologies used according their implementation degree and ranked from the highest implementation level to the lowest. This ranking compared to the simple use has changed. "Bi-/Tri-generation" is the EST with the greatest high implementation rate $(43 \%)$, together with "Product recovery," which is an MST. The second EST in the ranking of highly implemented technologies is "Highly efficient pumps" with $42 \%$. The "Speed regulation" technology was the most widely used technology, but only $31 \%$ of firms acknowledged strong use of this technology, giving it a ranking of 7 . This fact could be again related to the possible misunderstanding of the term "Speed regulation".

Nevertheless, a percentages variance of the highly implemented technologies is smaller compared with the percentages of the simple use of these technologies.
This fact is more evident for EST and less so for MST as both MST technologies are more widely used and both have relatively high extensive share of use. Only "Energy retrieval" technology and "Control system for shut down of machines in off-peak periods" technology have the smallest usage share in the "high use" group.

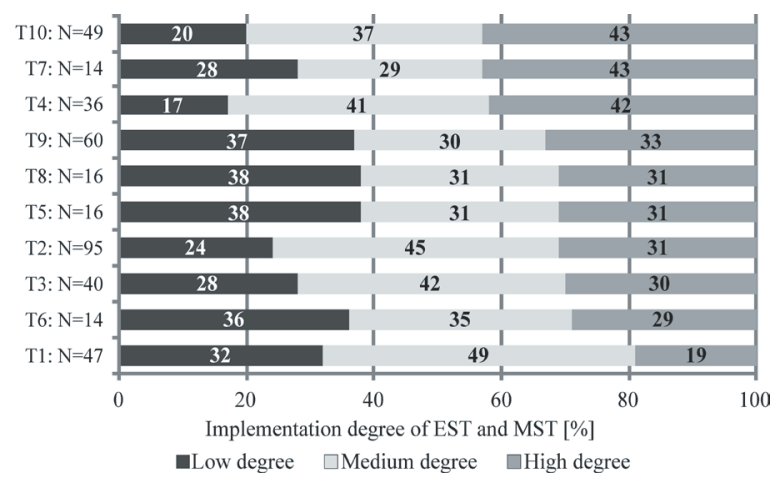

Fig. 2. Degree of implementation of EST and MST for all manufacturing sectors

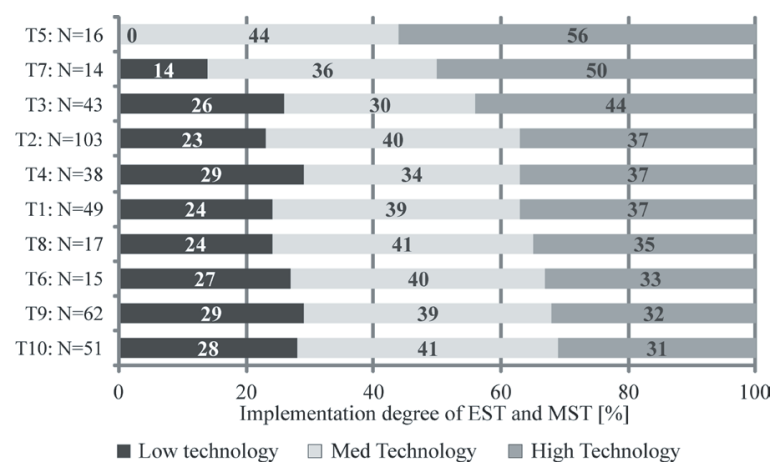

Fig. 3. Implementation percentage of EST and MST by technological sector

Fig. 3 presents EST and MST in accordance with the three technological intensity groups. The technologies are ranked based on the share of use in the "Medium-High and High technology" group (from the highest to the lowest share). "Lowtemperature joining processes" is the technology with the highest percentage of use in "Medium-High and High technology" with $56 \%$. No firm utilises this technology in the "Low technology" group. "Bi-/ Tri-generation" is the only other technology that is predominantly used in the "Medium-High and High technology" group with $50 \%$. We can see that none of these technologies is widely used in the "Low technology" group (firms in this group represent a percentage of the total used technologies, which is always below 30\%). On the other hand at least 30\% of the used technologies are within the "Medium-High and High technology" group (from 31 to 56\%). MST 
have the lowest use among firms in the "MediumHigh and High technology" group.

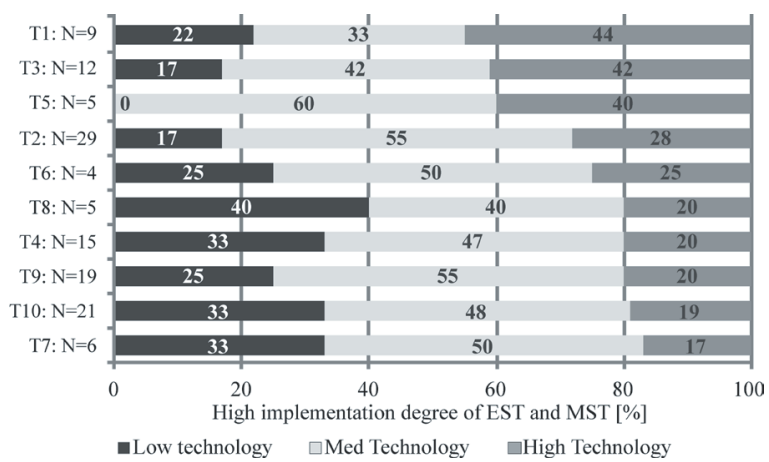

Fig. 4. High implementation percentage of EST and MST by technological sector

We have also analysed the use of highly implemented technologies according to three technological intensity groups (Fig. 4). The highly implemented technologies are ranked based on the share of use in the "Medium-High and High technology" group (from the highest to the lowest share). This ranking, compared to the general implementation degree, has changed. Interestingly, the average percentage of highly implemented technologies in the "Medium-High and High technology" group is lower than for the implementation of EST and MST in general. This leads to the conclusion that the analysed EST and MST are predominately highly implemented in low and medium-low technology groups.

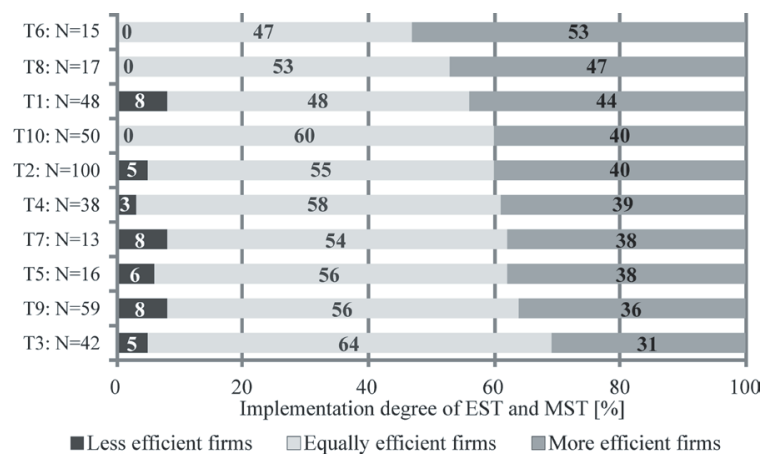

Fig. 5. Implementation percentage of EST and MST by level of efficiency relative to the sector

Fig. 5 presents EST and MST implementation in three groups that represent the relative energy and materials consumption efficiency in production. The technologies are ranked based on the share of use in the "More effective" group (from the highest to the lowest share). "Energy retrieval" is the technology with the highest share of the "More efficient" group with $53 \%$. No firm $(0 \%)$ in the "Less efficient" group uses either "Energy retrieval," "Waste material for energy" or "Product recovery.". "Energy retrieval" is the only technology most widely used in the "More efficient" group. All the other technologies are most widely used in the "Equally efficient" group (47 to $64 \%$ ), which represents $65 \%$ of the total number of firms. It is very obvious that EST and MST are hardly used in the "Less efficient" group, with a share always lower than $9 \%$. On the other hand at least $30 \%$ of the technologies are used within the "More efficient" group (from 31 to $53 \%$ ).

We have also analysed the use of highly implemented technologies according to three groups that represent the relative energy and materials consumption efficiency in production (Fig. 6). The highly implemented technologies are ranked based on the share of use in the "More effective" group (from the highest to the lowest share). This ranking has changed compared to the general implementation degree, but not very drastically. More importantly, we can see that the analysed EST and MST are usually highly implemented in firms that claim to be more energy efficient than other firms in their industry.

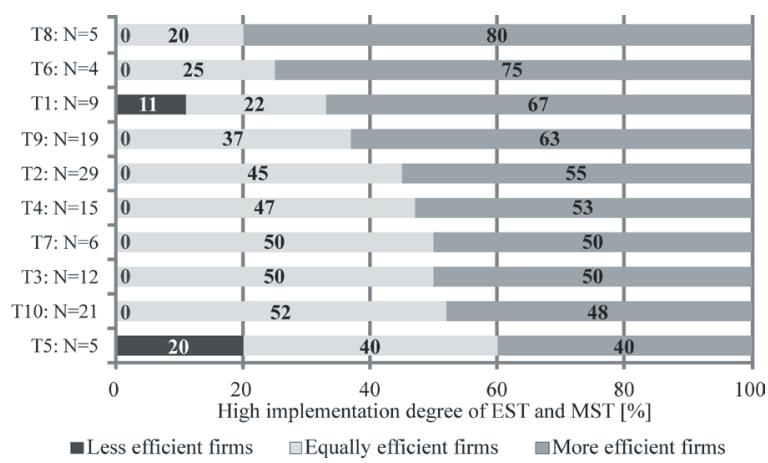

Fig. 6. High implementation percentage of EST and MST by level of efficiency relative to the sector

In order to test the possible relationship between technology level (intensity) and environmental management systems implementation and the number of EST and MST implemented or the number of these technologies highly implemented, several tests of correlation have been carried out (Tables 3 and 4). We conducted correlation tests using the Pearson correlation value.

Table 3 shows a correlation matrix between the firm's technology level and use and the high use of EST and MST. The results show that no significant correlation appears between technology level and EST and MST use and high use. 
Table 3. Correlation matrix between firm's technology level and use and high use of EST and MST

\begin{tabular}{|c|c|c|c|c|c|c|}
\hline & & $\begin{array}{l}\text { Technology } \\
\text { level }\end{array}$ & $\begin{array}{l}\text { Number of EST } \\
\text { implemented }\end{array}$ & $\begin{array}{l}\text { Number of } \\
\text { EST highly } \\
\text { implemented }\end{array}$ & $\begin{array}{l}\text { Number of } \\
\text { EST and MST } \\
\text { implemented }\end{array}$ & $\begin{array}{l}\text { Number of EST } \\
\text { and MST highly } \\
\text { implemented }\end{array}$ \\
\hline Technology level & $\begin{array}{l}\text { Pearson Correlation } \\
\text { Sig. (2-tailed) } \\
\text { N }\end{array}$ & $\begin{array}{r}1 \\
187\end{array}$ & $\begin{array}{r}0.076 \\
0.300 \\
187\end{array}$ & $\begin{array}{r}-0.021 \\
0.781 \\
187\end{array}$ & $\begin{array}{r}0.042 \\
0.565 \\
187\end{array}$ & $\begin{array}{r}-0.063 \\
0.390 \\
187\end{array}$ \\
\hline $\begin{array}{l}\text { Number of EST } \\
\text { implemented }\end{array}$ & $\begin{array}{l}\text { Pearson Correlation } \\
\text { Sig. (2-tailed) } \\
\mathrm{N}\end{array}$ & $\begin{array}{r}0.076 \\
0.300 \\
187 \\
\end{array}$ & $\begin{array}{r}1 \\
187 \\
\end{array}$ & $\begin{array}{r}0.531^{*} \\
0.000 \\
187 \\
\end{array}$ & $\begin{array}{r}0.927^{\star} \\
0.000 \\
187 \\
\end{array}$ & $\begin{array}{r}0.480 * \\
0.000 \\
187 \\
\end{array}$ \\
\hline $\begin{array}{l}\text { Number of EST highly } \\
\text { implemented }\end{array}$ & $\begin{array}{l}\text { Pearson Correlation } \\
\text { Sig. (2-tailed) } \\
\mathrm{N}\end{array}$ & $\begin{array}{r}0.076 \\
0.300 \\
187 \\
\end{array}$ & $\begin{array}{r}0.531^{\star} \\
0.000 \\
187 \\
\end{array}$ & $\begin{array}{r}1 \\
187 \\
\end{array}$ & $\begin{array}{r}0.509^{\star} \\
0.000 \\
187 \\
\end{array}$ & $\begin{array}{r}0.928^{\star} \\
0.000 \\
187 \\
\end{array}$ \\
\hline $\begin{array}{l}\text { Number of EST and } \\
\text { MST implemented }\end{array}$ & $\begin{array}{l}\text { Pearson Correlation } \\
\text { Sig. (2-tailed) } \\
\mathrm{N}\end{array}$ & $\begin{array}{r}0.042 \\
0.565 \\
187 \\
\end{array}$ & $\begin{array}{r}0.927^{\star} \\
0.000 \\
187\end{array}$ & $\begin{array}{r}0.509^{\star} \\
0.000 \\
187\end{array}$ & $\begin{array}{r}1 \\
187 \\
\end{array}$ & $\begin{array}{r}0.519^{*} \\
0.000 \\
187\end{array}$ \\
\hline $\begin{array}{l}\text { Number of EST } \\
\text { and MST highly } \\
\text { implemented }\end{array}$ & $\begin{array}{l}\text { Pearson Correlation } \\
\text { Sig. (2-tailed) } \\
\text { N }\end{array}$ & $\begin{array}{r}-0.063 \\
0.390 \\
187\end{array}$ & $\begin{array}{r}0.480^{*} \\
0.000 \\
187\end{array}$ & $\begin{array}{r}0.928^{\star} \\
0.000 \\
187\end{array}$ & $\begin{array}{r}0.519^{\star} \\
0.000 \\
187\end{array}$ & 187 \\
\hline
\end{tabular}

* Correlation is significant at the 0.01 level (2-tailed)

Table 4. Correlation matrix between environmental management systems use and the use and high use of EST and MST

\begin{tabular}{|c|c|c|c|c|c|c|}
\hline & & $\begin{array}{l}\text { Technology } \\
\text { level }\end{array}$ & $\begin{array}{l}\text { Number of EST } \\
\text { implemented }\end{array}$ & $\begin{array}{l}\text { Number of } \\
\text { EST highly } \\
\text { implemented }\end{array}$ & $\begin{array}{l}\text { Number of } \\
\text { EST and MST } \\
\text { implemented }\end{array}$ & $\begin{array}{l}\text { Number of EST } \\
\text { and MST highly } \\
\text { implemented }\end{array}$ \\
\hline Technology level & $\begin{array}{l}\text { Pearson Correlation } \\
\text { Sig. (2-tailed) } \\
\text { N }\end{array}$ & $\begin{array}{r}1 \\
187\end{array}$ & $\begin{array}{r}0.238^{\star} \\
0.001 \\
187\end{array}$ & $\begin{array}{r}0.056 \\
0.445 \\
187\end{array}$ & $\begin{array}{r}0.292^{\star} \\
0.000 \\
187\end{array}$ & $\begin{array}{r}0.087 \\
0.237 \\
187\end{array}$ \\
\hline $\begin{array}{l}\text { Number of EST } \\
\text { implemented }\end{array}$ & $\begin{array}{l}\text { Pearson Correlation } \\
\text { Sig. (2-tailed) } \\
\mathrm{N}\end{array}$ & $\begin{array}{r}0.238^{\star} \\
0.001 \\
187 \\
\end{array}$ & $\begin{array}{r}1 \\
187 \\
\end{array}$ & $\begin{array}{r}0.531^{\star} \\
0.000 \\
187 \\
\end{array}$ & $\begin{array}{r}0.927^{\star} \\
0.000 \\
187 \\
\end{array}$ & $\begin{array}{r}0.480 * \\
0.000 \\
187 \\
\end{array}$ \\
\hline $\begin{array}{l}\text { Number of EST highly } \\
\text { implemented }\end{array}$ & $\begin{array}{l}\text { Pearson Correlation } \\
\text { Sig. (2-tailed) } \\
\mathrm{N}\end{array}$ & $\begin{array}{r}0.056 \\
0.445 \\
187 \\
\end{array}$ & $\begin{array}{r}0.531^{\star} \\
0.000 \\
187 \\
\end{array}$ & $\begin{array}{r}1 \\
187 \\
\end{array}$ & $\begin{array}{r}0.509^{\star} \\
0.000 \\
187 \\
\end{array}$ & $\begin{array}{r}0.928 * \\
0.000 \\
187 \\
\end{array}$ \\
\hline $\begin{array}{l}\text { Number of EST and } \\
\text { MST implemented }\end{array}$ & $\begin{array}{l}\text { Pearson Correlation } \\
\text { Sig. (2-tailed) } \\
\mathrm{N}\end{array}$ & $\begin{array}{r}0.292^{*} \\
0.000 \\
187 \\
\end{array}$ & $\begin{array}{r}0.927^{\star} \\
0.000 \\
187 \\
\end{array}$ & $\begin{array}{r}0.509^{\star} \\
0.000 \\
187 \\
\end{array}$ & $\begin{array}{r}1 \\
187 \\
\end{array}$ & $\begin{array}{r}0.519 * \\
0.000 \\
187 \\
\end{array}$ \\
\hline $\begin{array}{l}\text { Number of EST } \\
\text { and MST highly } \\
\text { implemented }\end{array}$ & $\begin{array}{l}\text { Pearson Correlation } \\
\text { Sig. (2-tailed) } \\
\text { N }\end{array}$ & $\begin{array}{r}0.087 \\
0.237 \\
187\end{array}$ & $\begin{array}{r}0.480^{*} \\
0.000 \\
187\end{array}$ & $\begin{array}{r}0.928^{*} \\
0.000 \\
187\end{array}$ & $\begin{array}{r}0.519^{\star} \\
0.000 \\
187\end{array}$ & 187 \\
\hline
\end{tabular}

* Correlation is significant at the 0.01 level (2-tailed)

We also wanted to explore the relationship between environmental management systems use and the use and high use of EST and MST. As shown in Table 4, only the simple use of EST and MST is significantly correlated with environmental management systems such as ISO 14000 , but not with the high use of these technologies. In these cases, both Pearson correlation coefficients are significant at 0.01 level (2-tailed), and the one that also considers MST is higher than the one considering only EST. Consequently, the relationship strength is also slightly higher.

\section{CONCLUSIONS}

Based on our analysis five conclusions can be drawn. A general observation on the use of EST and MST is that the use of these technologies in manufacturing firms is still relatively low (from 8 to $35 \%$ ). The only exception is "Speed control" technology with $56 \%$. The first conclusion is that in analysing energy efficiency groups we have observed a slight decrease in the technological intensity values from the "Less efficient" group to the "More efficient" group. On the other hand, the Low Technology group has a slightly higher average of material and energy efficiency 
in production than the Medium-High and High technology group (3.25 vs. 3.18). Both these facts could reveal a possible negative relationship between energy efficiency in production and technological intensity of firms, at least on average. This suggests that firms in high technology industries focus less on energy efficiency than low technology firms.

Secondly, both MST are ranked second and third in general use. But it is interesting to note that they are mostly used in the low and medium technology sector, not in the high technology one. "Product recovery after product life cycle" is the most widely highly utilised technology, being mostly used in the low and medium technology sector.

Thirdly, only $7 \%$ of all manufacturing firms claims to be less energy efficient than firms from their sector, $30 \%$ believe they are more energy efficient than others. We calculate that MST and EST are on average used $41 \%$ in the more efficient group, $55 \%$ in the medium efficient group, and $4 \%$ in the less efficient group of firms. Based on this fact, manufacturing firms are more efficient if they use at least one EST or MST.

Fourthly, in analysing EST and MST we focused on manufacturing firms that showed high implementation of these technologies. We have analysed these technologies according to their use in different technology intensity sectors and based on the energy efficiency of the firms. We found that the analysed EST and MST are predominately highly implemented in low and medium-low technology groups and less so in the "Medium-High and High technology" group. This observation could again prove that firms in high technology industries focus less on energy efficiency than low technology firms. However, our results show that there is no significant correlation between technology level and the percentage of EST and MST use and high use.

On the other hand, the analysed EST and MST are usually highly implemented in firms that claim to be more energy efficient than other firms in their industry. This leads to a potentially positive relationship between being energy and material efficient and using energy efficient technologies, especially if they are highly implemented.

Our final conclusion concerns the implementation of environmental management systems. Our results showed a positive significant relationship between energy and material efficiency, but only with use (not high use) of these technologies.

Our research has several limitations. The first is that only descriptive statistics and correlation tests were used to map the characteristics of energy efficient technologies and their adopters. To draw further conclusions in the future several advanced statistical methods will have to be used (e. g. linear regression for quantitative independent variables and ordinal logistic regression). We will further explore the relationship between the implementation of energy efficient technologies and the environmental performance of manufacturing firms. In addition, we will also examine the use of these technologies and the economic performance of manufacturing firms. Another limitation is also the narrow geographical coverage and the fact that no similar previous data exists with which to compare our findings. This shortcoming is already being addressed by the inclusion of energy efficiency questions in the new European Manufacturing Survey 2012.

Despite these shortcomings, our contribution categorizes the use of energy efficient technologies, describes the characteristics of their adopters, and indicates a possible influence of these technologies on the environmental performance of manufacturing firms.

\section{REFERENCES}

[1] Marland, G., Boden, T.A., Andres, R.J. (2007). Global, Regional, and National $\mathrm{CO}_{2}$ Emissions. In Trends: A Compendium of Data on Global Change. Carbon Dioxide Information Analysis Center, Oak Ridge National Laboratory, US Department of Energy, Oak Ridge.

[2] Tseng, M.L., Lin, Y.H., Chiu, A.S.F. (2009). Fuzzy AHP-based study of cleaner production implementation in Taiwan PWB manufacturer. Journal of Cleaner Production, vol. 17, no. 14, p. 1249-1256, DOI:10.1016/j.jclepro.2009.03.022.

[3] Kliopova, I., Staniskis, J.K. (2006). The evaluation of cleaner production performance in Lithuanian industries. Journal of Cleaner Production, vol. 14, p. 1561-1575, DOI:10.1016/j.jclepro.2005.04.017.

[4] Lovrec, D., Tič, V. (2011). Energy saving coolingunit for plastic moulding machine. Strojniski vestnikJournal of Mechanical Engineering, vol. 57, no. 2, p. 83-90, DOI:10.5545/sv-jme.2010.082.

[5] Thollander, P. Danestig, M., Rohdin, P. (2007). Energy policies for increased industrial energy efficiency: Evaluation of a local energy programme for manufacturing SMEs. Energy Policy, vol. 35, p. 57745783, DOI:10.1016/j.enpol.2007.06.013.

[6] Tanaka, K. (2008). Assessment of energy efficiency performance measures in industry and their application for policy. Energy Policy, vol. 36, p. 2887-2902, DOI:10.1016/j.enpol.2008.03.032.

[7] International Energy Agency. (2008). Assessing Measures of Energy Efficiency Performance and Their 
Application in Industry. Retrieved on 19. 9. 2012, from http://www.iea.org/papers/2008/JPRG_Info_Paper.pdf.

[8] Bunse, K., Vodicka, M., Schönsleben, P., Brülhart, M., Ernst, F.O. (2011). Integrating energy efficiency performance in production management - gap analysis between industrial needs and scientific literature. Journal of Cleaner Production, vol. 19, p. 667-679, DOI:10.1016/j.jclepro.2010.11.011.

[9] International Energy Agency. (2009). Implementing Energy Efficiency Policies 2009. Are IEA Member Countries on Track? Retrieved on 19. 9. 2012, from http://www.gbv.de/dms/zbw/613955536.pdf.

[10] Mundaca, L. (2008). Markets for energy efficiency: exploring the implications of an EU-wide 'tradable white certificate' scheme. Energy Economics, vol. 30, p. 3016-3043, DOI:10.1016/j.eneco.2008.03.004.

[11] Li, W., Winter, M., Kara, S., Herrmann, C. (2012). Ecoefficiency of manufacturing processes: A grinding case. CIRP Annals - Manufacturing Technology, vol. 61, p. 59-62.

[12] Neelis, M., Ramirez-Ramirez, A., Patel, M., Farla, J., Boonekamp, P., Blok, K. (2007). Energy efficiency developments in the Dutch energy-intensive manufacturing industry, 1980-2003. Energy Policy, vol. 35, p. 6112-6131, DOI:10.1016/j.enpol.2007.06.014.

[13] De Groot, H.L.F., Verhoef, E.T., Nijkamp, P. (2001). Energy saving by firms: decision making, barriers and policies. Energy Economics, vol. 23, p. 717-740, DOI:10.1016/S0140-9883(01)00083-4.

[14] Paton, B. (2001). Efficiency gains within firms under voluntary environmental initiatives. Journal of Cleaner Production, vol. 9, p. 167-178, DOI:10.1016/S09596526(00)00068-8.

[15] Sancin, U., Dobravc, M., Dolšak, B. (2010). Human Cognition as an Intelligent Decision Support System for Plastic Products' Design. Expert Systems with Applications, vol. 37, no. 10, p. 7227-7233, DOI:10.1016/j.eswa.2010.04.005.

[16] Sardianou, E. (2008). Barriers to industrial energy efficiency investments in Greece. Journal of Cleaner Production, vol. 16, p. 1416-1423, DOI:10.1016/j. jclepro.2007.08.002.

[17] Tan, Y., Takakuwa. S. (2011). Use of Simulation in a Factory for Business Continuity Planning. International Journal of Simulation Modelling, vol. 10, no. 1, p. 1726, DOI:10.2507/IJSIMM10(1)2.172.

[18] Ang, B.W. (2006). Monitoring changes in economywide energy efficiency: from energy-GDP ratio to composite efficiency index. Energy Policy, vol. 34, 574-582, DOI:10.1016/j.enpol.2005.11.011.
[19] Patterson, M.G. (1996). What is energy efficiency? Concepts, indicators and methodological issues. Energy Policy, vol. 24, p. 377-390, DOI:10.1016/03014215(96)00017-1.

[20] Hammadi, M., Choley, J.Y., Penas, O., Louati, J., Rivière, A., Haddar, M. (2011). Layout optimization of power modules using a sequentially coupled approach. International Journal of Simulation Modelling, vol. 10, no. 3, p. 122-132, DOI:10.2507/IJSIMM10(3)2.183.

[21] Zhao, R. (2012). Simulation-based environmental cost analysis for work-in-process. International Journal of Simulation Modelling, vol. 11, no. 4, p. 211-224, DOI:10.2507/IJSIMM11(4)4.218.

[22] Phylipsen, D., Blok, K., Worrell, E., de Beer, J. (2002). Benchmarking the energy efficiency of Dutch industry: an assessment of the expected effect on energy consumption and $\mathrm{CO}_{2}$ emissions. Energy Policy, vol. 30, p. 663-679, DOI:10.1016/S0301-4215(02)00023-X.

[23] Farla, J., Blok, K., Schipper, L. (1997). Energy efficiency developments in the pulp and paper industry: a cross-country comparison using physical production data. Energy Policy, vol. 25, p. 745-758, DOI:10.1016/ S0301-4215(97)00065-7.

[24] Duhovnik, J., Žargi, U., Kušar, J., Starbek, M. (2009). Project-driven concurrent product development. Concurrent Engineering-Research and Applications, vol. 17, no. 3, p. 225-236, DOI:10.1177/1063293X09343823.

[25] International Energy Agency. (2007). Tracking Industrial, Energy Efficiency and $\mathrm{CO}_{2}$ Emissions. Retrieved on 20. 8. 2012, from http://www.iea.org/ textbase/nppdf/free/2007/tracking_emissions.pdf.

[26] Irrek, W., Thomas, S. (2006). Der Energie Spar Fonds für Deutschland. Hans-Böckler-Stiftung, Düsseldorf. (in German)

[27] Zeng, S.X., Meng, X.H., Yin, H.T., Tam, C.M., Sun, L. (2010). Impact of cleaner production on business performance. Journal of Cleaner Production, vol. 18, p. 975-983, DOI:10.1016/j.jclepro.2010.02.019.

[28] OECD (2005) Directorate for Science, Technology and Industry, stan indicators (2005 edition): 1980-2003. Organisation for Economic Cooperation and Development, Paris. Retrieved on 29. 9. 2012, from http://www.oecd.org/industry/ industryandglobalisation/40230754.pdf.

[29] ISO 14000. (2004). Environmental management The ISO 14000 family of International Standards. International Organization for Standardization. Geneva. 